Article

\title{
Heat Stress Reduces Root Meristem Size via Induction of Plasmodesmal Callose Accumulation Inhibiting Phloem Unloading in Arabidopsis
}

\author{
Jie Liu ${ }^{1}$, Yao Liu ${ }^{1}$, Shuang Wang ${ }^{1}$, Yongqi Cui ${ }^{1}$ and Dawei Yan ${ }^{1,2}, *(\mathbb{D})$ \\ 1 State Key Laboratory of Crop Stress Adaptation and Improvement, School of Life Sciences, Henan University, \\ Kaifeng 475001, China; liujie19900115@yeah.net (J.L.); m17633750636@163.com (Y.L.); \\ ws2020210@163.com (S.W.); 17698011118@163.com (Y.C.) \\ 2 Academy for Advanced Interdisciplinary Studies, Henan University, Kaifeng 475001, China \\ * Correspondence: ydw2019@henu.edu.cn
}

Citation: Liu, J.; Liu, Y.; Wang, S.; Cui, Y.; Yan, D. Heat Stress Reduces Root Meristem Size via Induction of Plasmodesmal Callose Accumulation Inhibiting Phloem Unloading in Arabidopsis. Int. J. Mol. Sci. 2022, 23, 2063. https://doi.org/10.3390/ ijms23042063

Academic Editor: Kenji Miura

Received: 18 January 2022

Accepted: 11 February 2022

Published: 13 February 2022

Publisher's Note: MDPI stays neutral with regard to jurisdictional claims in published maps and institutional affiliations.

Copyright: (C) 2022 by the authors. Licensee MDPI, Basel, Switzerland. This article is an open access article distributed under the terms and conditions of the Creative Commons Attribution (CC BY) license (https:// creativecommons.org/licenses/by/ $4.0 /)$.

\begin{abstract}
The intercellular transport of sugars, nutrients, and small molecules is essential for plant growth, development, and adaptation to environmental changes. Various stresses are known to affect the cell-to-cell molecular trafficking modulated by plasmodesmal permeability. However, the mechanisms of plasmodesmata modification and molecules involved in the phloem unloading process under stress are still not well understood. Here, we show that heat stress reduces the root meristem size and inhibits phloem unloading by inducing callose accumulation at plasmodesmata that connect the sieve element and phloem pole pericycle. Furthermore, we identify the loss-offunction of CALLOSE SYNTHASE 8 (CalS8), which is expressed specifically in the phloem pole pericycle, decreasing the plasmodesmal callose deposition at the interface between the sieve element and phloem pole pericycle and alleviating the suppression at root meristem size by heat stress. Our studies indicate the involvement of callose in the interaction between root meristem growth and heat stress and show that CalS8 negatively regulates the thermotolerance of Arabidopsis roots.
\end{abstract}

Keywords: callose; callose synthase; heat; root meristem; plasmodesmata; thermotolerance

\section{Introduction}

Phloem-mediated translocation of molecules including nutrients, proteins, RNAs, and hormones is critical for plant growth and development [1-6]. The process by which solutes exit the phloem, referred to as phloem unloading, regulates the molecular flux into sink organs to accommodate their high energy and signaling demands [7]. Phloem unloading is mostly active in growing sink tissues such as the root apex, and the restriction of phloem unloading impairs primary root growth $[7,8]$. Several regulators of phloem unloading have been identified up to now [8-12]. For example, knocking out two annexin genes in Arabidopsis-namely, ANNEXIN1 and ANNEXIN2-limited the unloading of sugars from the phloem to the root tip, and this restriction impaired primary root growth [8]. The PHLOEM UNLOADING MODULATOR gene regulates the early root elongation rate by controlling the extent of phloem unloading into the root meristem [9]. Plasmodesmata (PD)-mediated symplastic trafficking plays an important role in the unloading process [13]. PD are membrane-lined channels connecting adjacent cells, exhibiting diverse and dynamic morphology and inner structure at different cell layers and developmental stages of plants [14,15]. In Arabidopsis, solutes are batch-unloaded from protophloem sieve element (PSE) into the phloem-pole pericycle (PPP) facilitated by funnel-shaped PD [16], and subsequently move further into the endodermis [9]. This post-SE unloading process is modulated by the dynamic proportion of type I and type II PD at the PPP-endodermis interface $[9,17]$. 
Callose ( $\beta$-1,3-glucan) is known as a major regulator of plasmodesmal aperture and permeability, and its abundance is inversely associated with the trafficking efficiency through PD [18-20]. Dynamic callose turnover is achieved by the coordinated action of CalSs and $\beta$-1,3-glucanases (BGs) [21], and it regulates plant growth and development $[10,11,22]$. Gain-of-function mutations in CalS3 lead to callose deposition at the PD and impair the cell-cell movement, resulting in the inhibition of primary root growth [11]. In Arabidopsis, $\beta-1,3$-glucanase_putative PD-associated protein (BG_ppap), BG1, BG2, and BG6 regulate callose degradation at the PD [22-24]. The plasmodesmal permeability also appears to be regulated by PD-LOCALIZED PROTEINS (PDLPs) and PLASMODESMATA CALLOSEBINDING PROTEINS (PDCBs), of which the downstream targets are callose $[25,26]$. The mutants $p d l p 5$ and $p d c b 1$ showed increased PD permeability, whereas in the overexpression lines the intercellular trafficking was dramatically blocked $[25,26]$. Moreover, callose allows plants to rapidly coordinate symplastic signaling in response to abiotic stresses [20]. Chilling [27-29], wounding [30,31], and heavy metals [32-34] increase callose deposition at PD and inhibit root growth $[24,32,35,36]$. Given the rise in global temperature, heat has become one of the major stresses for plants [37]. Heat stress disturbs cellular homeostasis and impedes growth and development in plants [38]. In addition to the membrane damage, protein degradation, enzyme inactivation, and reactive oxygen species (ROS) accumulation, callose biosynthesis can also be induced by heat stress, even mild treatment [39-41]. However, very little is known about the mechanisms by which heat stress induces callose deposition.

The Arabidopsis genome encodes 12 CalS proteins, and some of them show PD localization and specific expression patterns $[11,16,21]$. An inducible cals $3 m$ system under the CalS8 promoter ( $p$ CalS8::icals $3 m$ ) promotes callose accumulation in the PPP cells and reduces the PD permeability, leading to the blockage of symplastic PSE-PPP connection and the subsequent impaired phloem unloading and root growth [16]. CalS8 has been recognized as a key callose synthase modulating plasmodesmata-mediated trafficking in response to ROS-associated stress, since its absence arrests the induction of callose in response to $\mathrm{H}_{2} \mathrm{O}_{2}$ treatment and wounding [31]. These results confirm the inducible activity of CalS8 and imply the reasonable speculation of the possible role of CalS8 in modulating phloem unloading. In this study, we aimed to investigate whether heat stress affects root meristem size by inducing callose biosynthesis and which callose synthase is involved in this process. We found heat stress induces callose deposition at SE-PPP and PPP-endodermis interfaces, inhibits phloem unloading, and restricts the meristem size in Arabidopsis roots. Furthermore, we proved the loss of CalS8 rescue the inhibition phenotype under heat stress due to the defect in callose accumulation around PD at the SE-PPP interface within the unloading zone of the root tip. Our study provides evidence suggesting CalS 8 acts as a negative modulator of plasmodesmata-mediated trafficking in response to heat stress in the root.

\section{Results}

\subsection{Heat Stress Reduces Root Meristem Size and Inhibits Phloem Unloading}

To examine the impact of heat stress on primary root growth, we transferred 5-day-old wild-type Arabidopsis thaliana (Col-0) seedlings germinated and grown on normal 1/2 MS medium at $22{ }^{\circ} \mathrm{C}$ to $30{ }^{\circ} \mathrm{C}$ to grow continually. After 3- and 4-day treatment, we measured the elongation of newly grown primary roots and found the length was significantly shorter at $30^{\circ} \mathrm{C}$ compared with $22^{\circ} \mathrm{C}$ (Figure $1 \mathrm{~A}, \mathrm{~B}$ ). Similarly, the growth rate was also slower at $30^{\circ} \mathrm{C}$ (Figure 1C). To assess the effect of high temperature in detail, we further examined the root meristem under both temperatures. Consistent with the change in root elongation, plants growing at $30^{\circ} \mathrm{C}$ showed an evident reduction in the meristem size and cell number (Figure 1D-F). 
A

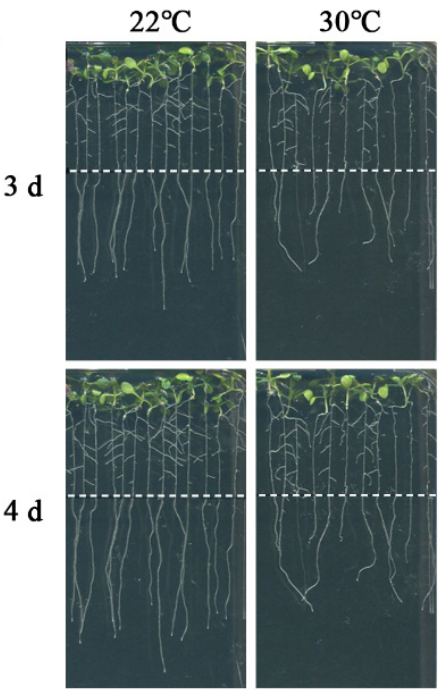

D

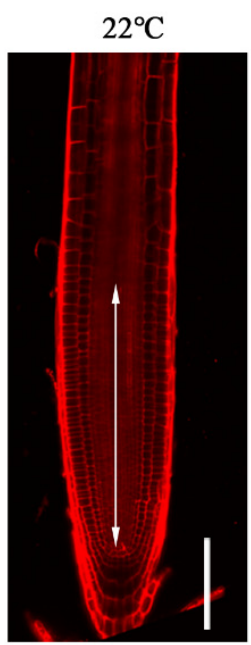

B

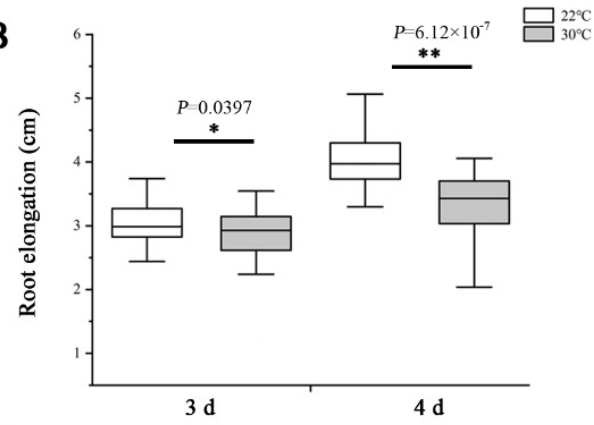

C

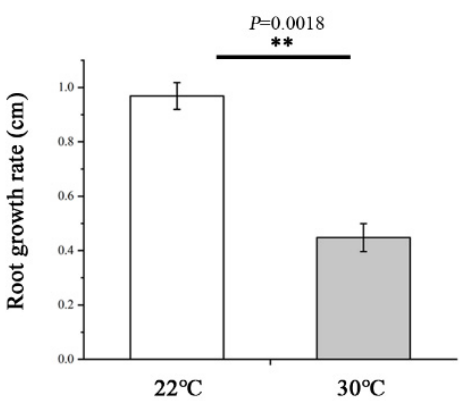

$\mathrm{E}$

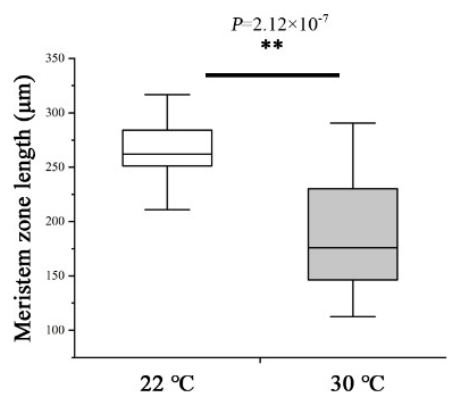

$\mathrm{F}$

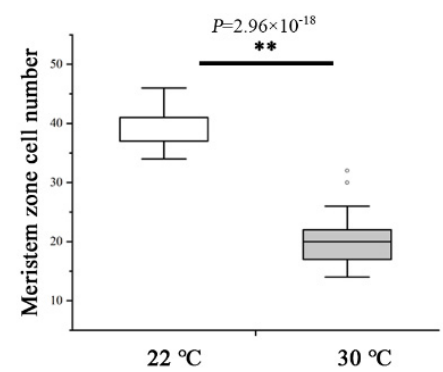

Figure 1. Heat stress reduces root meristem size in Arabidopsis thaliana. (A) Five-day-old wild-type (WT) seedlings grown on $1 / 2 \mathrm{MS}$ medium were transferred to $22^{\circ} \mathrm{C}$ and $30{ }^{\circ} \mathrm{C}$ and cultivated vertically for $3 \mathrm{~d}$ and $4 \mathrm{~d}$ and photographed. Dashed lines show the initial positions of root tips after being transferred. (B) Quantification of the length of newly grown primary roots in A, $n>34$. (C) Quantification of the growth rate in A. The data are means \pm SE. (D) Five-day-old roots of WT were transferred to $22^{\circ} \mathrm{C}$ and $30^{\circ} \mathrm{C}$ for $48 \mathrm{~h}$ and stained with propidium iodide to visualize the cell walls. Double arrows indicate the meristem length (from the cortical initial cell to the first elongated cell in the cortex layer). Scale bars $=100 \mu \mathrm{m}$. (E) Quantification of the root meristem length in $\mathrm{D}$, $n>20$. (F) Quantification of the cell number of meristem in $\mathrm{D}, n>20$. In the box plots $(\mathbf{B}, \mathbf{E}, \mathbf{F})$, the boxes indicate the first and third quartiles, and the whiskers indicate the minimum and maximum values. The black lines within the boxes indicate the median values. Outliers are shown as dots. ${ }^{* *} p<0.01 ;{ }^{*} p<0.05$ (two-tailed, two-sample $t$-test). 
To determine the effect of heat stress on phloem unloading, we analyzed the phloem unloading using the transgenic plants expressing SUC2::GFP as mobile marker. GFP was expressed in companion cells and then transported and unloaded from the SE into PPP and diffused further via PD throughout the entire root meristem [10,16]. At $48 \mathrm{~h}$ after transfer to $30{ }^{\circ} \mathrm{C}$, the GFP fluorescence intensity of the region of interest (ROI) 1 in the root tip was much weaker than that of the roots still growing at $22^{\circ} \mathrm{C}$ (Figure 2A,B). To quantify the unloading capability from the phloem into the meristem, we calculated the ratio of GFP fluorescence intensity of an ROI1 relative to an ROI2. Under the control condition of $22{ }^{\circ} \mathrm{C}$, approximately $73 \%$ GFP was moved from the phloem to the meristem (Figure 2D). Whereas at $30^{\circ} \mathrm{C}$, the GFP unloading ratio was inhibited dramatically and decreased to $45 \%$ (Figure 2D). These results suggest that heat stress impedes the phloem unloading and limits the molecular flux to the root meristem, conferring the inhibition of primary root growth.

A

A

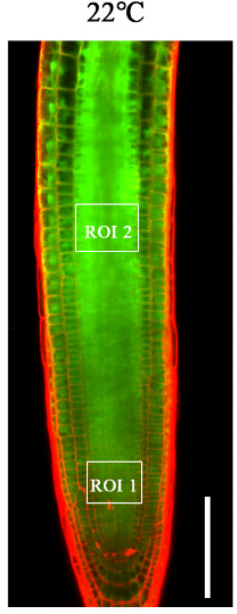

$\mathrm{C}$

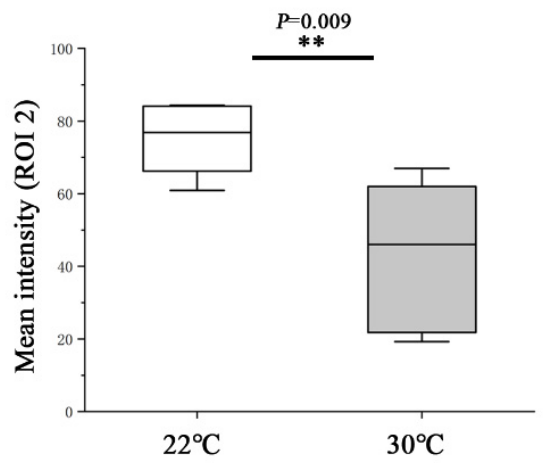

B

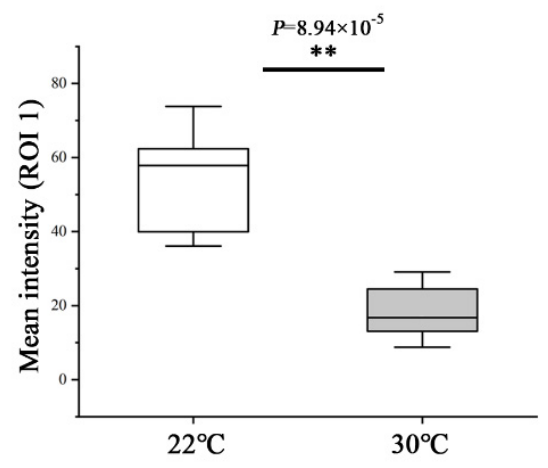

D

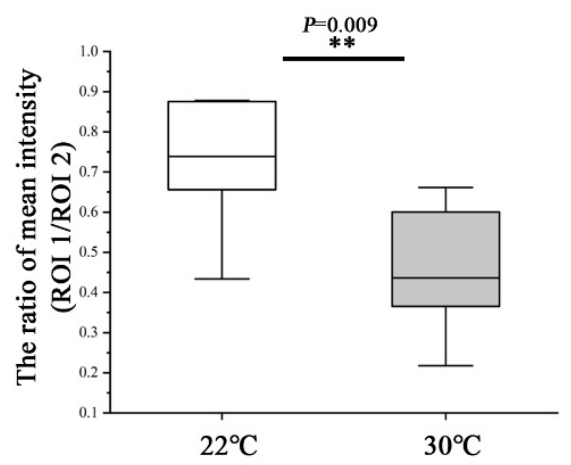

Figure 2. Heat stress inhibits phloem unloading in the root tips. (A) Comparison of the phloem unloading in the root of pSUC2::GFP-expressing 5-day-old seedlings at $48 \mathrm{~h}$ after being transferred to $22{ }^{\circ} \mathrm{C}$ and $30^{\circ} \mathrm{C}$. Scale bars $=100 \mu \mathrm{m}$. (B) Quantification of fluorescence intensity in an area of $50 \times 40 \mu \mathrm{m}^{2}$ (ROI1, $50 \mu \mathrm{m}$ away from quiescent center (QC) in the central root meristem). (C) Quantification of fluorescence intensity in an area of $50 \times 40 \mu \mathrm{m}^{2}$ (ROI2, $300 \mu \mathrm{m}$ away from QC in the stele). (D) Quantification the unloading capability from the phloem into the meristem by the ratio of GFP fluorescence intensity of an ROI1 relative to an ROI2. In the box plots (B-D), the boxes indicate the first and third quartiles, and the whiskers indicate the minimum and maximum values. The black lines within the boxes indicate the median values. ${ }^{* *} p<0.01$ (two-tailed, two-sample $t$-test).

\subsection{Heat Stress Induces Plasmodesmal Callose Accumulation within Unloading Zone}

It is known that PD-mediated symplastic movement regulates phloem unloading in the root, and the callose turnover controls the plasmodesmal permeability $[13,16,20]$. To 
determine the influence of heat on PD conductivity, callose levels at PD were assessed by immunolocalization using a callose antibody on root sections derived from the unloading domain. We examined the plasmodesmal callose signals at both the SE-PPP and PPPendodermal interfaces. The root tips of Col- 0 seedlings transferred to $30^{\circ} \mathrm{C}$ for $24 \mathrm{~h}$ showed a significant increase in callose amount at both interfaces, compared with that growing at $22{ }^{\circ} \mathrm{C}$ (Figure 3). These results indicate that the restriction of GFP unloading into the root meristem in response to heat stress resulted from excessive callose deposition at PD within the unloading zone, and this overproduction affected both the SE and post-SE unloading.

A
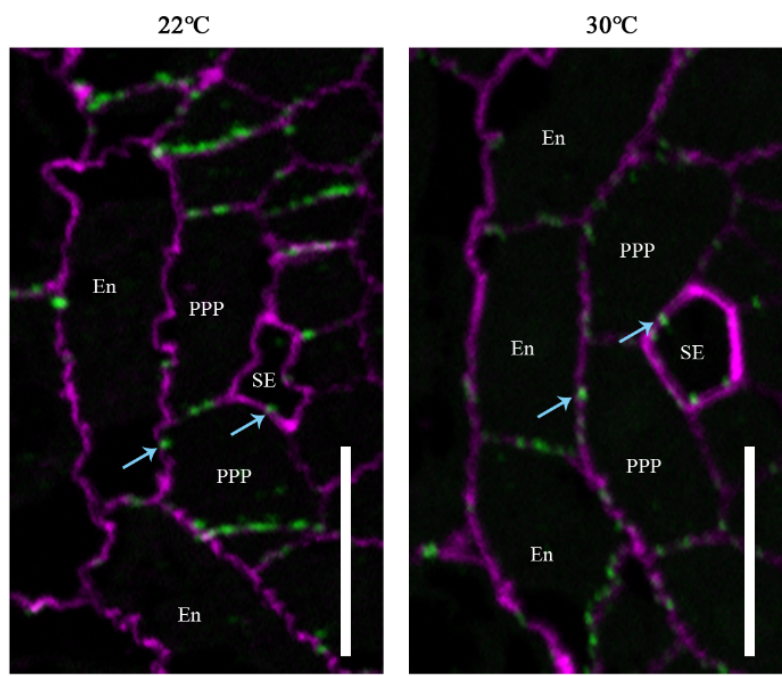

B

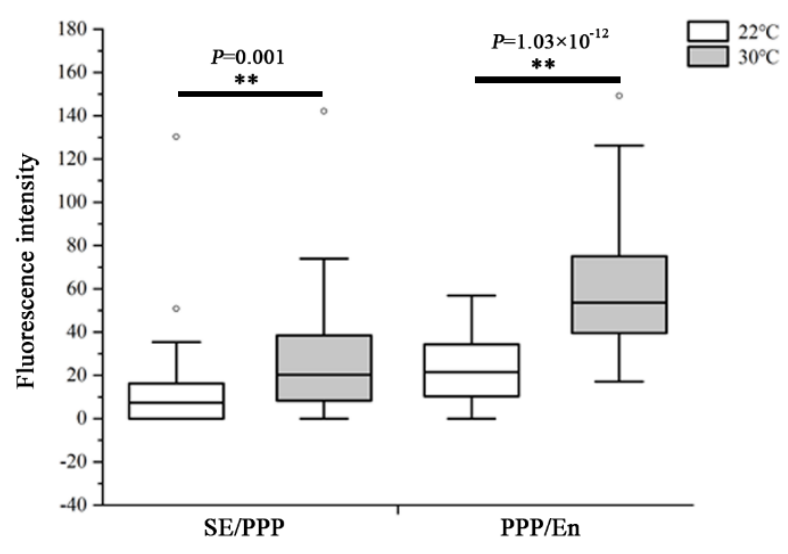

Figure 3. Heat stress induces callose deposition at SE-PPP and PPP-endodermal interfaces within the unloading zone. (A) Immunolocalization of callose at plasmodesmata (blue arrows) at the SE-PPP and PPP-endodermis interfaces in the same region of the unloading domain (200 $\mu \mathrm{m}$ upward of QC) in the root tips of Col-0 at $24 \mathrm{~h}$ after transferred to $22^{\circ} \mathrm{C}$ and $30^{\circ} \mathrm{C}$. Scale bars $=10 \mu \mathrm{m}$. (B) Mean fluorescence intensity of the callose signals are calculated in ImageJ. In the box plots, the boxes indicate the first and third quartiles, and the whiskers indicate the minimum and maximum values. The black lines within the boxes indicate the median values. Outliers are shown as dots. ${ }^{* *} p<0.01$ (two-tailed, two-sample $t$-test).

\subsection{CalS8 Regulates the Plasmodesmal Callose Deposition under Heat Stress}

To identify the candidate genes contributing to the callose accumulation involved in the heat response, we focused on the 12 Arabidopsis callose synthases. Based on their expression patterns and our previous work, we selected CalS8 and CalS6 as candidates due to their enrichment in the PPP cells [16] (Supplementary Figure S1). In targeting these two genes, we 
screened potential transfer T-DNA insertion lines and identified one putative cals6 mutant and two cals8 mutant alleles: cals6, cals8-1, and cals8-2 (Supplementary Figure S2A,C). The corresponding transcripts were knocked out in cals8-1 and cals6 (Supplementary Figure S2B,D), which were thus used for further studies.

To determine the effects while CalS8 and CalS6 are absent, we examined the plasmodesmal callose levels in cals8-1 and cals6 mutants using the same method after the same heat treatment as above. Unlike the wild-type Col-0 plants, callose accumulation at the SE-PPP interfaces in the cals8-1 roots were not increased when transferred to $30{ }^{\circ} \mathrm{C}$ from $22{ }^{\circ} \mathrm{C}$. Conversely, callose is also increased significantly at the PPP-endodermal interface in cals8-1 (Figure 4). These data suggest that CalS8 is responsible for the plasmodesmal callose induction by heat stress at only the SE-PPP interfaces.

A

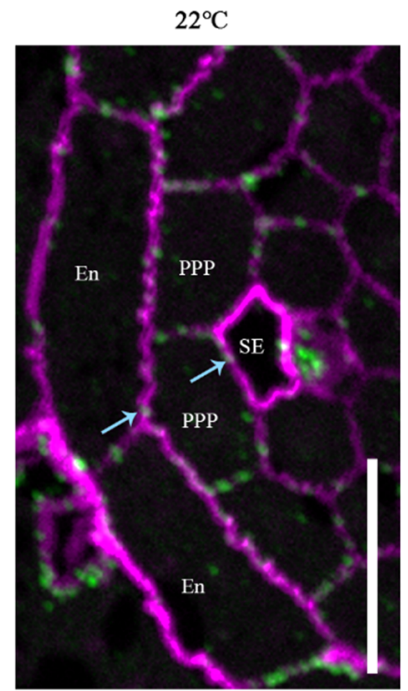

B

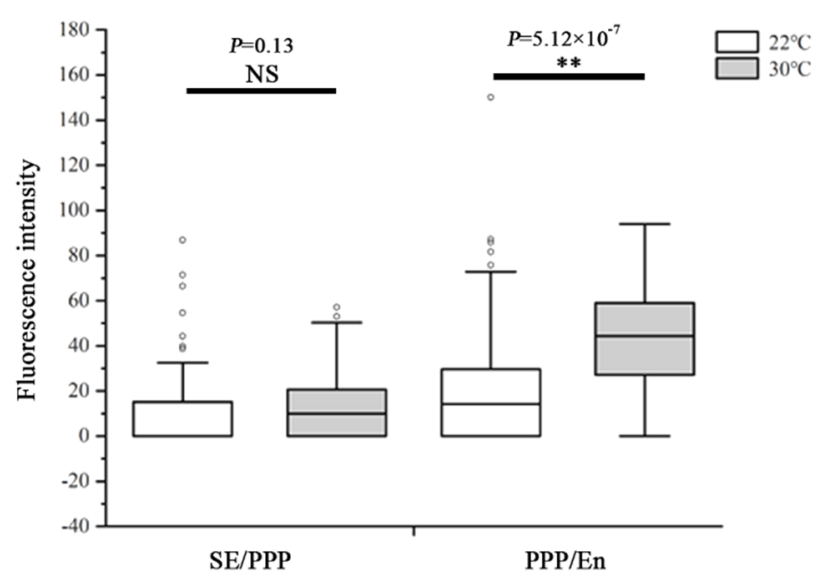

Figure 4. CalS8 is a bona fide callose synthase required for heat stress-induced callose deposition. (A) Immunolocalization of callose at plasmodesmata (blue arrows) at the SE-PPP and PPPendodermis interfaces in the same region of the unloading domain (200 $\mu \mathrm{m}$ upward of QC) in the root tips of cals8- 1 at $24 \mathrm{~h}$ after transferred to $22{ }^{\circ} \mathrm{C}$ and $30^{\circ} \mathrm{C}$. Scale bars $=10 \mu \mathrm{m}$. (B) Mean fluorescence intensity of the callose signals are calculated in ImageJ. In the box plots, the boxes indicate the first and third quartiles, and the whiskers indicate the minimum and maximum values. The black lines within the boxes indicate the median values. Outliers are shown as dots. ${ }^{* *} p<0.01$ (two-tailed, two-sample $t$-test). NS, not significant.

To test whether the reducing callose levels could ameliorate the inhibition of heat stress on primary root meristem growth, we compared the meristem length of cals8-1 mutant 
and wild-type Col- 0 roots after being transferred to $30^{\circ} \mathrm{C}$ and $22{ }^{\circ} \mathrm{C}$ for $48 \mathrm{~h}$. Unlike the decreased meristem size of Col- 0 roots at $30{ }^{\circ} \mathrm{C}$, there was almost no difference in cals $8-1$ under these two conditions (Figure 5), indicating the enhanced thermotolerance of cals8-1. Nevertheless, this resistance was not exhibited in cals6 mutant (Supplementary Figure S3). Overall, these results suggest a novel role of CalS 8 in the callose-mediated root meristem size inhibition under heat stress.

A

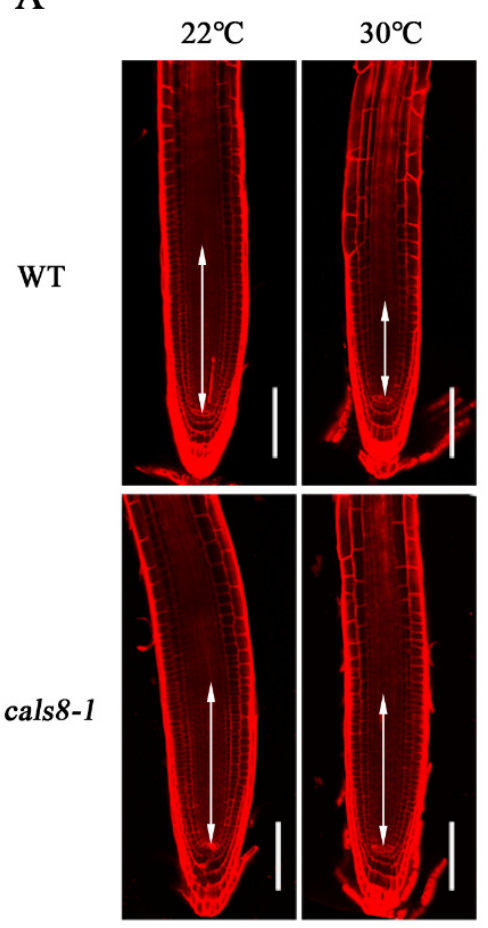

B

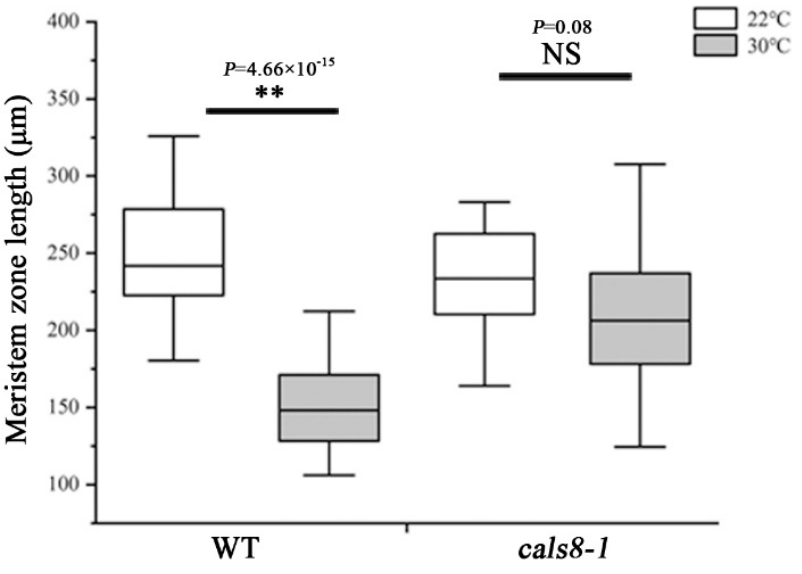

Figure 5. Loss of CalS8 rescues the decrease in meristem size under heat stress. (A) Five-day-old roots of WT and cals8- 1 were transferred to $22{ }^{\circ} \mathrm{C}$ and $30{ }^{\circ} \mathrm{C}$ for $48 \mathrm{~h}$ and stained with propidium iodide to visualize the cell walls. Double arrows indicate the meristem zone. Scale bars $=100 \mu \mathrm{m}$. (B) Quantification of the meristem length in A, $n>20$. In the box plots, the boxes indicate the first and third quartiles, and the whiskers indicate the minimum and maximum values. The black lines within the boxes indicate the median values. ${ }^{* *} p<0.01$ (two-tailed, two-sample $t$-test). NS, not significant.

\subsection{CalS8 Expression Is Not Influenced by Heat Stress}

To explore how the heat regulates the CalS 8 function, we further tested whether the heat-induced callose deposition was accompanied by an elevated level of CalS8 gene transcription. We first treated the transgenic plants harboring the CalS8pro::YFPer construct at $30^{\circ} \mathrm{C}$ for $24 \mathrm{~h}$. No significant difference in YFP reporter activity was observed at $30{ }^{\circ} \mathrm{C}$ and normal $22{ }^{\circ} \mathrm{C}$ (Figure 6A,B). We next verified this result by reverse transcription quantitative PCR (RT-qPCR). The expression level of CalS8 were also hardly affected by heat stress (Figure 6C). Taken together, these data suggest that the callose induction at $\mathrm{PD}$ in response to the heat stress is not due to transcriptional activation of the CalS8 gene. It remains to be tested whether this callose response is a result of post-transcriptional modification or activity promotion at the protein/enzyme level.

Callose levels are regulated by the opposing activities of two enzyme families: callose synthases and $\beta-1,3$-glucanases, which produce and break down callose, respectively [21]. PDLPs and PDCBs are two key proteins families that positively regulate callose accumulation at PD $[25,26]$. We next used RT-qPCR to confirm the expression of PD callose associated genes, including the remaining eleven CalSs, four $\beta-1,3-$ glucanases (BG_PPAP, BG1, BG2, $B G 6)$, eight $P D L P s$, and five $P D C B$ s. As shown in Figure 7 , no dramatic and significant upregulation in their expression levels was detected after heat treatment. This suggests that 
the heat stress probably does not interfere with callose biosynthesis via regulating most of the associated genes at the transcriptional level.

A

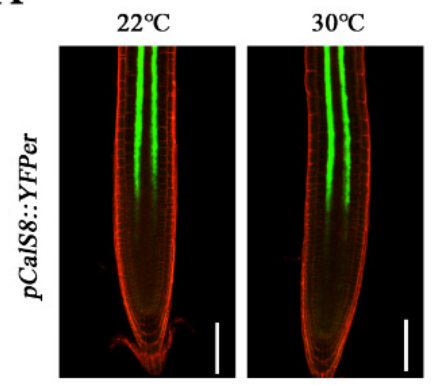

B

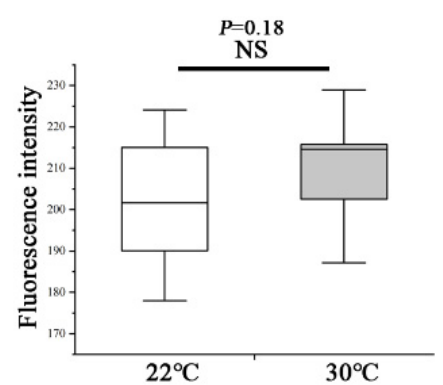

C

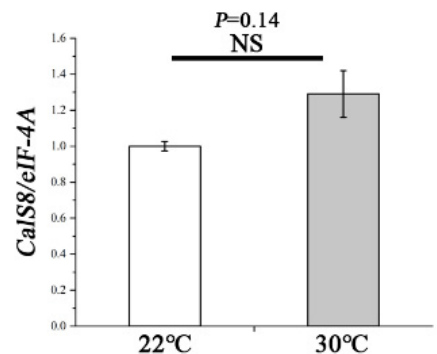

Figure 6. Transcript-level expression of CalS8 is not influenced by heat stress. (A) Images of pCalS8::YFPer-expressing 5-day-old seedlings roots $24 \mathrm{~h}$ after transfer to $22{ }^{\circ} \mathrm{C}$ and $30{ }^{\circ} \mathrm{C}$. Scale bars $=100 \mu \mathrm{m}$. (B) Quantification of fluorescence intensity in A using ImageJ. (C) Comparison of the relative transcript levels of CalS8 in the root tips of Col-0 seedlings at $24 \mathrm{~h}$ after being transferred to $22^{\circ} \mathrm{C}$ and $30^{\circ} \mathrm{C}$. Data are based on three independent replicate experiments. Data are means $\pm \mathrm{SD}$. In the box plots $(\mathbf{B})$, the boxes indicate the first and third quartiles, and the whiskers indicate the minimum and maximum values. The black lines within the boxes indicate the median values. Significant differences were determined by the two-tailed, two-sample $t$-test. NS, not significant.

A

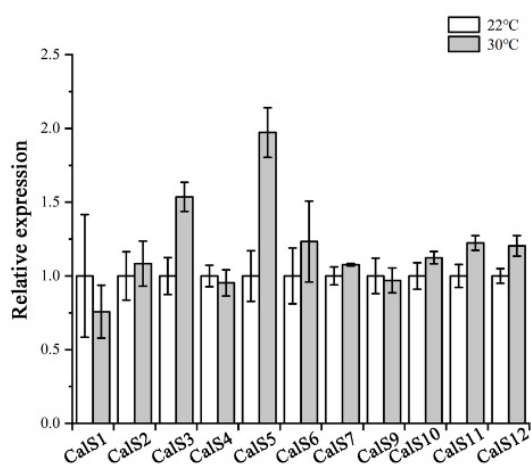

C

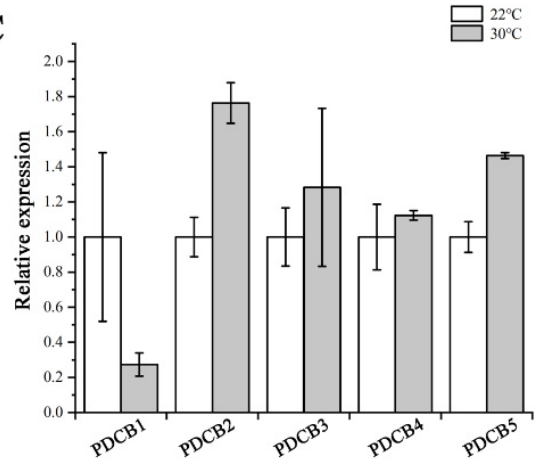

B

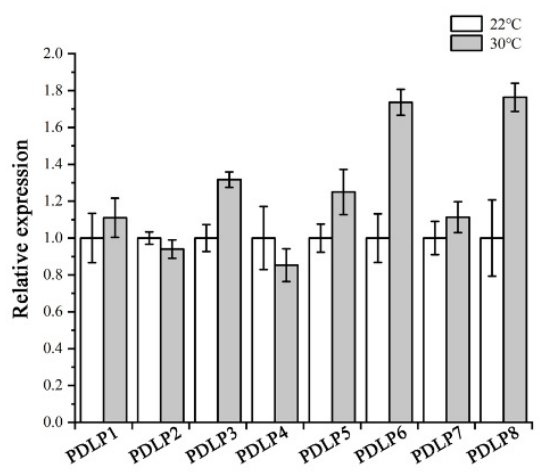

D

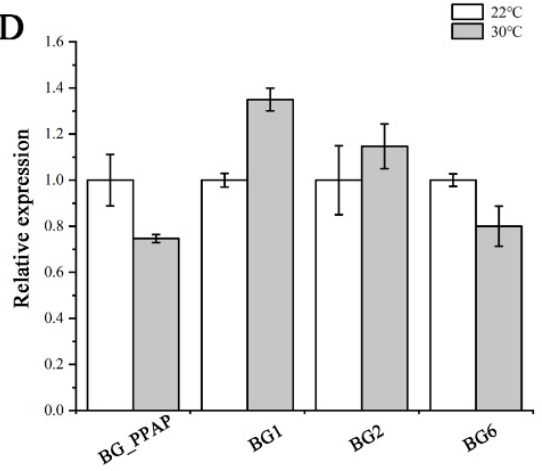

Figure 7. Expression of callose-associated genes after heat stress treatment. Quantitative RT-PCR analysis of CalSs (A), PDLPS (B), PDCBs (C), and BGs (D) transcript levels in root tips of Col-0 after $24 \mathrm{~h}$ heat stress treatment. Total RNA was isolated from root tips. eIF-4A was used as an internal control. Three independent experiments were performed. Data are means $\pm \mathrm{SE}$ of three biological repetitions, $n=3$. 


\section{Discussion}

Roots encounter various environmental challenges during development and respond by modulating their growth $[42,43]$. The root meristem is organized by stem cells that generate all cell types of the root [44]. The rates of cell production in the meristem and differentiation in the elongation/differentiation zone homeostatically maintain the meristem size. Under stresses, abnormal changes including deficient nutrient supply, altered hormone distribution, dysfunction of signaling, division/differentiation activities of transition zone, and meristematic zone regulate the root meristem size $[24,42,43,45-50]$. Heat stress impairs cell cycle, induces callose accumulation, impedes the carbon transport, and consequently inhibits the tissue growth [38-41,51]. Here, we find the mild heat stress $\left(30^{\circ} \mathrm{C}\right)$ reduces the root meristem size via callose-dependent suppression of source-to-sink phloem translocation. Our data uncover a new way of heat stress influencing root growth, while the mechanism of how the cell division is regulated during this process is worthy of further investigation.

Our current study provides evidence that CalS8 contributes to the heat stress-induced plasmodesmal responses, but the upstream signaling components that coordinate plasmodesmal callose accumulation and permeability remain unclear. Several studies highlight a correlation between ROS levels and callose deposition at PD and the roles of ROS in the regulation of heat responses in plants $[10,31,35,52]$. CalS8 has been characterized as a vital regulator mediating ROS-induced plasmodesmal callose deposition [31]. This raises the hypothesis that ROS might be an essential molecular link that integrates the heat stress with the restriction in plasmodesmal permeability caused by CalS8. The receptor-like proteins (RLPs) or receptor-like kinases (RLKs) are a highly expanded family of transmembrane proteins in plants and are largely responsible for communication between cells and the extracellular environmental stimuli [53]. The two extracellular DUF26 domains in RLPs and RLKs may be able to sense the apoplastic ROS status [54,55]. RLPs or RLKs, therefore, may be the candidates of the upstream regulators of CalS8 activity under heat stress, which needs more evidence.

Callose is one of the most active components of the cell wall due to its dynamic deposition and degradation. At plasmodesmata, the turnover of callose controls the plasmodesmal permeability and symplastic transport and consequently affects plant development and stress responses $[10,11,18,22]$. Our previous study indicated that phloem pole pericycle cells are the main mediator of unloading [9]. Overproduction of callose in the phloem pole pericycle compromises phloem unloading and root growth by blocking plasmodesmata [16]. We thus proposed that callose synthase that exhibits activity in the phloem pole pericycle might possess the ability of regulating phloem unloading. In this study, we found heat stress induces callose accumulation around plasmodesmata at both interfaces of sieve element-phloem pole pericycle and phloem pole pericycle-endodermis, and thus results in the inhibition of phloem unloading and root growth. Our data of root meristem analysis indicate that this inhibition by heat stress is probably initiated from a reduction in the meristematic cell proliferation. Nonetheless, this inhibition is suppressed by loss-of-function of CalS8, a callose synthase gene expressing specifically in the phloem pole pericycle. The root meristem grows almost normally, and the induction of callose deposition at plasmodesmata in the root unloading zone is reduced in cals8-1 mutant under heat stress, suggesting a negative role of CalS8 in thermotolerance. Unlike CalS8, the loss-of-function of CalS6, another callose synthase gene having similar expression pattern in phloem and phloem pole pericycle, does not show the rescued phenotype, indicating the functional divergence of callose synthases [21,56-58]. CalS8 is previously proved to be involved in the basal and ROS-dependent plasmodesmal permeability in leaves [31]. In our study, we found the basal plasmodesmal callose levels at both the SE-PPP and PPP-endodermal interfaces were not altered in cals8-1 mutant under normal growth temperature (Figures 3 and 4), suggesting a potential functional redundancy with other CalSs in regulating plasmodesmal callose homeostasis for phloem unloading. Overall, these data indicate the possible specific role of CalS8 in the heat-induced callose accumulation and root growth inhibition. Removal of 
CalS8 is thus enhancing the thermotolerance of Arabidopsis, and similarly, it gives us a clue that investigating the homologous callose synthases that express in the phloem unloading zone and are induced by stress in crop plants would be of help for the improvement of stress-resistant species.

Based on the data of functioning in callose biosynthesis and plasmodesmata blockage [11,16,31], CalS8 is supposed to be localized at plasmodesmata or plasma membrane like other callose synthases [11]. Nevertheless, we failed to generate the stable clones of fluorescent protein-tagged CalS8 after many attempts, as well as did another research group [31]. Although the details of CalS8 localization remain unavailable, we found loss of CalS8 arrests the induced plasmodesmal callose synthesis at the SE-PPP interface specifically but not the PPP-endodermis interface under heat stress. This suggests a possible biased localization of CalS8 at the SE-PPP interface or the existence of a compensation mechanism at the PPP-endodermis interface, which is worth investigating further. This might also imply the difference in functional regulation between SE-PPP and PPP-endodermis interfaces, although they are two connective key barriers for phloem unloading $[9,13]$.

As with many other stresses, high temperature interferes with callose biosynthesis [59-61]. CalS8 is involved in not only wounding-induced [31] but also heat-induced callose deposition and plasmodesmal regulation (Figure 4). Nonetheless, the transcript levels of CalS8 were not altered significantly under both stress conditions [31] (Figure 6). We hence proposed such stresses might be able to regulate the upstream of CalS8 or promote callose accumulation quickly via post-transcriptional modification or enzymatic activity regulation of CalS8 protein. Moreover, the expression levels of positive regulators of callose synthesis in our profile were all not increased dramatically under heat stress, with the fold changes less than 2 (Figure 7). Additionally, their expression patterns are not specific in phloem pole pericycle like CalS8 [11,62,63]. We therefore propose that, given that the minor expression changes are imputable, they might contribute to the accumulation of callose in other tissues and other biological processes rather than the plasmodesmal callose impairing phloem unloading and root growth under heat stress.

\section{Materials and Methods}

\subsection{Plant Materials and Growth}

Arabidopsis ecotype Col-0 was used as the wild type. cals8-1 (SALK_037603), cals8-2 (SALK_076074), and cals6 (SALK_022651C) were obtained from the Nottingham Arabidopsis Stock Centre (Nottingham, UK). The pSUC2::GFP lines were obtained from Ykä Helariutta's lab (Cambridge, UK), and the pCalS8::YFPer line was obtained from Jung-Youn Lee's lab (Newark, DE, USA). Seeds were sterilized in a solution containing $0.5 \%$ sodium hypochlorite and $0.1 \%$ Triton X-100 for $15 \mathrm{~min}$, washed five times with sterilized water, and grown vertically in Petri dishes on $1 / 2$ MS basal salt mixture with $0.7 \%$ Phytogel (Sigma-Aldrich, St. Louis, MO, USA), 1\% sucrose, and 0.05\% 4-morpholine ethanesulfonic acid (MES) at $\mathrm{pH} 5.8$ in a growth chamber at $22{ }^{\circ} \mathrm{C}$ under $16 \mathrm{~h}$ light $/ 8 \mathrm{~h}$ dark conditions.

\subsection{Root Growth Analysis}

For heat treatment, seeds were germinated vertically for $5 \mathrm{~d}$ at $22{ }^{\circ} \mathrm{C}$ before being transferred to $22^{\circ} \mathrm{C}$ and $30^{\circ} \mathrm{C}$. The seedlings were photographed, and primary root length was measured 3 and 4 days after transfer. The meristem length and cell number were measured $48 \mathrm{~h}$ after transfer.

\subsection{Callose Immunolocalization}

Callose detection was conducted as described before $[9,11]$. Five-day-old wild-type and mutant seedlings were transferred to $22{ }^{\circ} \mathrm{C}$ and $30{ }^{\circ} \mathrm{C}$ for $24 \mathrm{~h}$ and then fixed in fixative solution containing $4 \%$ paraformaldehyde and $0.5 \%$ glutaraldehyde in $0.1 \mathrm{M}$ PBS at pH 7.2 overnight at $4{ }^{\circ} \mathrm{C}$. Roots were collected and washed with PBS and water and pre-embedded in low-melting agarose. The samples then were dehydrated with ethanol of different concentration gradients $(25 \%, 50 \%, 70 \%, 90 \%, 96 \%, 3 \times 100 \%)$ for $30 \mathrm{~min}$ each 
step. After resin infiltration by increasing resin concentrations (LR white medium grade, $33 \%, 66 \%, 3 \times 100 \%$ ), polymerization was conducted overnight at $60{ }^{\circ} \mathrm{C}$. Selected the unloading domain where $200 \mu \mathrm{m}$ upward of Quiescent center and performed $1 \mu \mathrm{m}$ semithin sections on Leica EM UC7. Callose immunolocalization sections were incubated with diluted primary antibodies (monoclonal antibody against $(1 \rightarrow 3)-\beta$-glucan (Biosupplies), 1:1000) and secondary antibodies (Alexa Fluor Plus 488 goat anti-mouse IgG, 1:1000). Slides were finally mounted in a 1:1 solution of AF1 antifading agent (Citifluor) and $1 \times$ PBS, with the addition of calcofluor as a cell wall counterstain and scanned by confocal microscope.

\subsection{Phloem Unloading Assay}

Five-day-old seedlings expressing pSUC2::GFP were transferred to $22^{\circ} \mathrm{C}$ and $30{ }^{\circ} \mathrm{C}$ for $48 \mathrm{~h}$, respectively, and roots were imaged by confocal microscope for quantifying GFP fluorescence. Propidium iodide was used as a counter stain for the cell wall. Ratiometric data were analyzed by taking fluorescence intensity ratios in an ROI at $50 \mu \mathrm{m}$ above the QC relative to an ROI at $300 \mu \mathrm{m}$ away from QC in the stele in ImageJ.

\subsection{Transcriptional Analyses}

To quantify the expression levels of mRNA, root tips from 5-day-old seedlings were harvested after being transferred to $22{ }^{\circ} \mathrm{C}$ and $30{ }^{\circ} \mathrm{C}$ for $24 \mathrm{~h}$. Total RNA was extracted by hot phenol method and then treated with RNase-free DNase I (Takara, Shiga, Japan) to remove genomic DNA. Complementary DNAs were synthesized from total RNA primed with oligo(dT)18 primers using M-MLV reverse transcriptase (Takara) according to the user's manual. Semi-quantitative PCR for cals8-1, cals8-2, and cals6 was performed using specific primers across the T-DNA insertion site and $e I F-4 A$ as an internal standard. Quantitative PCRs were performed using gene-specific primers and real-time PCR mix (Roche, Basel, Switzerland) in a LightCycler 480 Real-Time PCR System (Roche) with a standard program for 40 cycles. The levels of gene expression were calculated relative to $e I F-4 A$. The primer sequences are listed in Supplementary Table S1.

\subsection{Confocal Imaging}

All confocal images were obtained by Nikon/A1 confocal laser scanning microscope. Images of callose immunolocalization were scanned under a water-immersion $60 \times$ objective at $\times 2$ digital zoom, and images for phloem unloading assay and meristem growth measurements were scanned under $20 \times$ objective. Excitation and emission wavelength were, respectively, $405 \mathrm{~nm}$ and $420-470 \mathrm{~nm}$ for calcofluor, $488 \mathrm{~nm}$ and $489-505 \mathrm{~nm}$ for GFP, and $561 \mathrm{~nm}$ and 600-650 $\mathrm{nm}$ for propidium iodide.

Supplementary Materials: The following supporting information can be downloaded at: https: / / www.mdpi.com/article/10.3390/ijms23042063/s1.

Author Contributions: D.Y. and J.L. designed the experiments; J.L. and Y.L. carried out most of the experiments with the assistance from S.W.; and Y.C., D.Y., J.L. and Y.L. wrote the manuscript. All authors have read and agreed to the published version of the manuscript.

Funding: This work was supported by the National Natural Science Foundation of China (32070192) and the Scientific Research Foundation for Advanced Talents of Henan University.

Institutional Review Board Statement: Not applicable.

Informed Consent Statement: Not applicable.

Data Availability Statement: Not applicable.

Conflicts of Interest: The authors declare that the research was conducted in the absence of any commercial or financial relationships that could be construed as potential conflict of interest. 


\section{References}

1. López-Salmerón, V.; Cho, H.; Tonn, N.; Greb, T. The phloem as a mediator of plant growth plasticity. Curr. Biol. 2019, 29 , 173-181. [CrossRef] [PubMed]

2. Turgeon, R.; Wolf, S. Phloem transport: Cellular pathways and molecular trafficking. Annu. Rev. Plant Biol. 2009, 60, 207-221. [CrossRef]

3. De Schepper, V.; De Swaef, T.; Bauweraerts, I.; Steppe, K. Phloem transport: A review of mechanisms and controls. J. Exp. Bot. 2013, 64, 4839-4850. [CrossRef] [PubMed]

4. Atkins, C.A.; Smith, P.M.; Rodriguez-Medina, C. Macromolecules in phloem exudates-a review. Protoplasma 2011, $248,165-172$. [CrossRef] [PubMed]

5. Turnbull, C.G.; Lopez-Cobollo, R.M. Heavy traffic in the fast lane: Long-distance signalling by macromolecules. New Phytol. 2013, 198, 33-51. [CrossRef]

6. Ham, B.K.; Lucas, W.J. The angiosperm phloem sieve tube system: A role in mediating traits important to modern agriculture. J. Exp. Bot. 2014, 65, 1799-1816. [CrossRef]

7. Oparka, K.J.; Duckett, C.M.; Prior, D.A.M.; Fisher, D.B. Real-time imaging of phloem unloading in the root tip of Arabidopsis Plant J. 1994, 6, 759-766. [CrossRef]

8. Wang, J.; Song, J.; Clark, G.; Roux, S.J. ANN1 and ANN2 Function in post-phloem sugar transport in root tips to affect primary root growth. Plant Physiol. 2018, 178, 390-401. [CrossRef]

9. Yan, D.; Yadav, S.R.; Paterlini, A.; Nicolas, W.J.; Petit, J.D.; Brocard, L.; Belevich, I.; Grison, M.S.; Vaten, A.; Karami, L.; et al Sphingolipid biosynthesis modulates plasmodesmal ultrastructure and phloem unloading. Nat. Plants 2019, 5, 604-615. [CrossRef]

10. Benitez-Alfonso, Y.; Cilia, M.; San Roman, A.; Thomas, C.; Maule, A.; Hearn, S.; Jackson, D. Control of Arabidopsis meristem development by thioredoxin-dependent regulation of intercellular transport. Proc. Natl. Acad. Sci. USA 2009, 106, 3615-3620. [CrossRef] [PubMed]

11. Vatén, A.; Dettmer, J.; Wu, S.; Stierhof, Y.D.; Miyashima, S.; Yadav, S.R.; Roberts, C.J.; Campilho, A.; Bulone, V.; Lichtenberger, R.; et al. Callose biosynthesis regulates symplastic trafficking during root development. Dev. Cell. 2011, 21, 1144-1155. [CrossRef] [PubMed]

12. Dettmer, J.; Ursache, R.; Campilho, A.; Miyashima, S.; Belevich, I.; O’Regan, S.; Mullendore, D.L.; Yadav, S.R.; Lanz, C.; Beverina, L.; et al. CHOLINE TRANSPORTER-LIKE1 is required for sieve plate development to mediate long-distance cell-to-cell communication. Nat. Commun. 2014, 5, 4276. [CrossRef]

13. Yan, D.; Liu, Y. Diverse regulation of plasmodesmal architecture facilitates adaptation to phloem translocation. J. Exp. Bot. 2020, 71, 2505-2512. [CrossRef] [PubMed]

14. Zambryski, P. Plasmodesmata. Curr. Biol. 2008, 18, 324-325. [CrossRef]

15. Zambryski, P.; Crawford, K. PLASMODESMATA: Gatekeepers for cell-to-cell transport of developmental signals in plants. Annu. Rev. Cell Dev. Biol. 2000, 16, 393-421. [CrossRef] [PubMed]

16. Ross-Elliott, T.J.; Jensen, K.H.; Haaning, K.S.; Wager, B.M.; Knoblauch, J.; Howell, A.H.; Mullendore, D.L.; Monteith, A.G.; Paultre, D.; Yan, D.; et al. Phloem unloading in Arabidopsis roots is convective and regulated by the phloem-pole pericycle. eLife 2017, 6, e24125. [CrossRef]

17. Nicolas, W.J.; Grison, M.S.; Trépout, S.; Gaston, A.; Fouché, M.; Cordelières, F.P.; Oparka, K.; Tilsner, J.; Brocard, L.; Bayer, E.M. Architecture and permeability of post-cytokinesis plasmodesmata lacking cytoplasmic sleeves. Nat. Plants 2017, 3, 17082. [CrossRef] [PubMed]

18. De Storme, N.; Geelen, D. Callose homeostasis at plasmodesmata: Molecular regulators and developmental relevance. Front. Plant Sci. 2014, 5, 138. [CrossRef]

19. Amsbury, S.; Kirk, P.; Benitez-Alfonso, Y. Emerging models on the regulation of intercellular transport by plasmodesmataassociated callose. J. Exp. Bot. 2017, 69, 105-115. [CrossRef]

20. Wu, S.-W.; Kumar, R.; Iswanto, A.B.B.; Kim, J.-Y. Callose balancing at plasmodesmata. J. Exp. Bot. 2018, 69, 5325-5339. [CrossRef]

21. Chen, X.Y.; Kim, J.Y. Callose synthesis in higher plants. Plant Signal Behav. 2009, 4, 489-492. [CrossRef] [PubMed]

22. Benitez-Alfonso, Y.; Faulkner, C.; Pendle, A.; Miyashima, S.; Helariutta, Y.; Maule, A. Symplastic intercellular connectivity regulates lateral root patterning. Dev. Cell. 2013, 26, 136-147. [CrossRef]

23. Levy, A.; Erlanger, M.; Rosenthal, M.; Epel, B.L. A plasmodesmataassociated $\beta$-1,3-glucanase in Arabidopsis. Plant J. 2007, 49, 669-682. [CrossRef]

24. O'Lexy, R.; Kasai, K.; Clark, N.; Fujiwara, T.; Sozzani, R.; Gallagher, K.L. Exposure to heavy metal stress triggers changes in plasmodesmatal permeability via deposition and breakdown of callose. J. Exp. Bot. 2018, 69, 3715-3728. [CrossRef]

25. Simpson, C.; Thomas, C.; Findlay, K.; Bayer, E.; Maule, A.J. An Arabidopsis GPI-anchor plasmodesmal neck protein with callose binding activity and potential to regulate cell-to-cell trafficking. Plant Cell. 2009, 21, 581-594. [CrossRef] [PubMed]

26. Lee, J.-Y.; Wang, X.; Cui, W.; Sager, R.; Modla, S.; Czymmek, K.; Zybaliov, B.; van Wijk, K.; Zhang, C.; Lu, H.; et al. A plasmodesmata-localized protein mediates crosstalk between cell-to-cell communication and innate immunity in Arabidopsis. Plant Cell. 2011, 23, 3353-3373. [CrossRef]

27. Rinne, P.L.; van den Boogaard, R.; Mensink, M.G.; Kopperud, C.; Kormelink, R.; Goldbach, R.; van der Schoot, C. Tobacco plants respond to the constitutive expression of the tospovirus movement protein $\mathrm{NS}_{\mathrm{M}}$ with a heat-reversible sealing of plasmodesmata that impairs development. Plant J. 2005, 43, 688-707. [CrossRef] 
28. Bilska, A.; Sowiński, P. Closure of plasmodesmata in maize (Zea mays) at low temperature: A new mechanism for inhibition of photosynthesis. Ann. Bot. 2010, 106, 675-686. [CrossRef] [PubMed]

29. Fromm, J.; Hajirezaei, M.R.; Becker, V.K.; Lautner, S. Electrical signaling along the phloem and its physiological responses in the maize leaf. Front. Plant Sci. 2013, 4, 239. [CrossRef]

30. Xie, B.; Wang, X.; Zhu, M.; Zhang, Z.; Hong, Z. CalS7 encodes a callose synthase responsible for callose deposition in the phloem. Plant J. 2011, 65, 1-14. [CrossRef]

31. Cui, W.; Lee, J.-Y. Arabidopsis callose synthases CalS1/8 regulate plasmodesmal permeability during stress. Nat. Plants 2016, 2, 16034. [CrossRef] [PubMed]

32. Sivaguru, M.; Fujiwara, T.; Šamaj, J.; Baluška, F.; Yang, Z.; Osawa, H.; Maeda, T.; Mori, T.; Volkmann, D.; Matsumoto, H. Aluminum-induced $1 \rightarrow 3-\beta$-D-glucan inhibits cell-to-cell trafficking of molecules through plasmodesmata. A new mechanism of aluminum toxicity in plants. Plant Physiol. 2000, 124, 991-1006. [CrossRef] [PubMed]

33. Ueki, S.; Citovsky, V. Identification of an interactor of cadmium ioninduced glycine-rich protein involved in regulation of callose levels in plant vasculature. Proc. Natl. Acad. Sci. USA 2005, 102, 12089-12094. [CrossRef] [PubMed]

34. Samardakiewicz, S.; Krzesłowska, M.; Bilski, H.; Bartosiewicz, R.; Woźny, A. Is callose a barrier for lead ions entering Lemna minor L. root cells? Protoplasma 2012, 249, 347-351. [CrossRef]

35. Müller, J.; Toev, T.; Heisters, M.; Teller, J.; Moore, K.L.; Hause, G.; Dinesh, D.C.; Bürstenbinder, K.; Abel, S. Iron-dependent callose deposition adjusts root meristem maintenance to phosphate availability. Dev. Cell. 2015, 33, 216-230. [CrossRef]

36. Zhang, H.; Shi, W.L.; You, J.F.; Bian, M.D.; Qin, X.M.; Yu, H.; Liu, Q.; Ryan, P.R.; Yang, Z.M. Transgenic Arabidopsis thaliana plants expressing a $\beta$-1,3-glucanase from sweet sorghum (Sorghum bicolor L.) show reduced callose deposition and increased tolerance to aluminium toxicity. Plant Cell Environ. 2015, 38, 1178-1188. [CrossRef]

37. Hoegh-Guldberg, O.; Jacob, D.; Taylor, M.; Bindi, M.; Brown, S.; Camilloni, I.; Diedhiou, A.; Djalante, R.; Ebi, K.; Engelbrecht, F.; et al. Chapter 3: Impacts of $1.5^{\circ} \mathrm{C}$ global warming on natural and human systems. In Global Warming of $1.5^{\circ} \mathrm{C}$. An IPCC Special Report on the Impacts of Global Warming of $1.5^{\circ} \mathrm{C}$ above Preindustrial Levels and Related Global Greenhouse Gas Emission Pathways, in the Context of Strengthening the Global Response to the Threat of Climate Change; Specical Report; Intergovernmental Panel on Climate Change: Geneva, Switzerland, 2018; pp. 175-311.

38. Wahid, A.; Gelani, S.; Ashraf, M.; Foolad, M. Heat tolerance in plants: An overview. Environ. Exp. Bot. 2007, 61, 199-223. [CrossRef]

39. McNairn, R.B.; Currier, H.B. Translocation blockage by sieve plate callose. Planta 1968, 82, 369-380. [CrossRef]

40. Smith, M.M.; McCully, M.E. Mild Temperature "Stress" and Callose Synthesis. Planta 1977, 136, 65-70. [CrossRef]

41. Dinar, M.; Rudich, J.; Zamski, E. Effects of heat stress on carbon transport from tomato leaves. Ann. Bot. 1982, 51, 130-133. [CrossRef]

42. Dastidar, M.G.; Scarpa, A.; Mägele, I.; Ruiz-Duarte, P.; von Born, P.; Bald, L.; Jouannet, V.; Maizel, A. ARF5/MONOPTEROS directly regulates miR390 expression in the Arabidopsis thaliana primary root meristem. Plant Direct. 2019, 3, e00116. [CrossRef]

43. Yamada, M.; Han, X.; Benfey, P.N. RGF1 controls root meristem size through ROS signalling. Nature 2020, 577, 85-88. [CrossRef] [PubMed]

44. Heidstra, R.; Sabatini, S. Plant and animal stem cells: Similar yet different. Nat. Rev. Mol. Cell Biol. 2014, 15, 301-312. [CrossRef] [PubMed]

45. Dello Ioio, R.; Linhares, F.S.; Scacchi, E.; Casamitjana-Martinez, E.; Heidstra, R.; Costantino, P.; Sabatini, S. Cytokinins determine Arabidopsis root-meristem size by controlling cell differentiation. Curr. Biol. 2007, 17, 678-682. [CrossRef]

46. Yang, L.; Zhang, J.; He, J.; Qin, Y.; Hua, D.; Duan, Y.; Chen, Z.; Gong, Z. ABA-Mediated ROS in Mitochondria Regulate Root Meristem Activity by Controlling PLETHORA Expression in Arabidopsis. PLoS Genet. 2014, 10, e1004791. [CrossRef]

47. Liu, W.; Li, R.J.; Han, T.T.; Cai, W.; Fu, Z.W.; Lu, Y.T. Salt stress reduces root meristem size by nitric oxide-mediated modulation of auxin accumulation and signaling in Arabidopsis. Plant Physiol. 2015, 168, 343-356. [CrossRef] [PubMed]

48. Jiang, K.; Moe-Lange, J.; Hennet, L.; Feldman, L.J. Salt stress affects the redox status of Arabidopsis root meristems. Front. Plant Sci. 2016, 7, 81. [CrossRef]

49. Ercoli, M.F.; Ferela, A.; Debernardi, J.M.; Perrone, A.P.; Rodriguez, R.E.; Palatnik, J.F. GIF transcriptional coregulators control root meristem homeostasis. Plant Cell 2018, 30, 347-359. [CrossRef]

50. Zhang, M.-L.; Huang, P.-P.; Ji, Y.; Wang, S.; Wang, S.-S.; Li, Z.; Guo, Y.; Ding, Z.; Wu, W.-H.; Wang, Y. KUP9 maintains root meristem activity by regulating $\mathrm{K}^{+}$and auxin homeostasis in response to low K. EMBO Rep. 2020, 21, e50164. [CrossRef]

51. Takahashi, N.; Ogita, N.; Takahashi, T.; Taniguchi, S.; Tanaka, M.; Seki, M.; Umeda, M. A regulatory module controlling stress-induced cell cycle arrest in Arabidopsis. eLife 2019, 8, e43944. [CrossRef]

52. Katano, K.; Honda, K.; Suzuki, N. Integration between ROS regulatory systems and other signals in the regulation of various types of heat responses in plants. Int. J. Mol. Sci. 2018, 19, 3370. [CrossRef] [PubMed]

53. Kimura, S.; Waszczak, C.; Hunter, K.; Wrzaczek, M. Bound by fate: The role of reactive oxygen species in receptor-like kinase signaling. Plant Cell. 2017, 29, 638-654. [CrossRef] [PubMed]

54. Idänheimo, N.; Gauthier, A.; Salojärvi, J.; Siligato, R.; Brosché, M.; Kollist, H.; Mähönen, A.P.; Kangasjärvi, J.; Wrzaczek, M. The Arabidopsis thaliana cysteine-rich receptor-like kinases CRK6 and CRK7 protect against apoplastic oxidative stress. Biochem. Biophys. Res. Commun. 2014, 445, 457-462. [CrossRef] [PubMed] 
55. Faulkner, C.; Petutschnig, E.; Benitez-Alfonso, Y.; Beck, M.; Robatzek, S.; Lipka, V.; Maule, A.J. LYM2-dependent chitin perception limits molecular flux via plasmodesmata. Proc. Natl. Acad. Sci. USA 2013, 110, 9166-9170. [CrossRef] [PubMed]

56. Verma, D.P.S.; Hong, Z. Plant callose synthase complexes. Plant Mol. Biol. 2001, 47, 693-701. [CrossRef]

57. Feng, J.; Chen, Y.; Xiao, X.; Qu, Y.; Li, P.; Lu, Q.; Huang, J. Genome-wide analysis of the CalS gene family in cotton reveals their potential roles in fiber development and reponses to stress. Peer J. 2021, 9, e12557. [CrossRef]

58. Guerriero, G.; Piasecki, E.; Berni, R.; Xu, X.; Legay, S.; Hausman, J.-F. Identification of callose synthases in stinging nettle and analysis of their expression in different tissues. Int. J. Mol. Sci. 2020, 21, 3853. [CrossRef]

59. Sager, R.; Lee, J.-Y. Plasmodesmata in integrated cell signalling insights from development and environmental signals and stresses. J. Exp. Bot. 2014, 65, 6337-6358. [CrossRef]

60. Hunter, K.; Kimura, S.; Rokka, A.; Tran, H.C.; Toyota, M.; Kukkonen, J.P.; Wrzaczek, M. CRK2 Enhances Salt tolerance by regulating callose deposition in connection with PLD $\alpha 1$. Plant Physiol. 2019, 180, 2004-2021. [CrossRef]

61. Parrotta, L.; Faleri, C.; Guerriero, G.; Cai, G. Cold stress affects cell wall deposition and growth pattern in tobacco pollen tubes. Plant Sci. 2019, 283, 329-342. [CrossRef]

62. Winter, D.; Vinegar, B.; Nahal, H.; Ammar, R.; Wilson, G.V.; Provart, N.J. An “Electronic Fluorescent Pictograph” browser for exploring and analyzing large-scale biological data sets. PLoS ONE 2007, 2, e718. [CrossRef] [PubMed]

63. Dong, X.; Hong, Z.; Sivaramakrishnan, M.; Mahfouz, M.; Verma, D.P. Callose synthase (CalS5) is required for exine formation during microgametogenesis and for pollen viability in Arabidopsis. Plant J. 2005, 42, 315-328. [CrossRef] [PubMed] 